\title{
Effects of ART on CD4 Count and Body Weight in HIV/AIDS Patients using Longitudinal Analysis in the Case of Debre Berhan Referral Hospital
}

\author{
A. R. Muralidharan ${ }^{1 *}$, Ayele Admasu' ${ }^{1}$ \\ ${ }^{1}$ Assistant Professor, Department of Statistics, College of Natural and Computational Sciences, Debre Berhan University, \\ Ethiopia
}

*Address for Correspondence: Dr. A. R. Muralidharan, Department of Statistics, College of Natural and Computational Sciences, Debre Berhan University, Ethiopia

E-mail: mdharan75@gmail.com

Received: 08 Feb 2020/ Revised: 12 May 2020/ Accepted: 27 June 2020

\begin{abstract}
Background: HIV/AIDS is one of the serious human health problems in the developing countries specially in Sub-Saharan Africa, including Ethiopia. This study carried out to reduce HIV-related morbidity and mortality, improving the quality of life of people with human immunodeficiency virus (HIV) under anti-retroviral therapy (ART). HIV attacks an immune cell, CD4 ${ }^{+}$cell and weight loss are associated with HIV/AIDS.

Methods: This is a retrospective longitudinal study for 4 years carried out from the data of patients initiated to ART, starting from July 2014 to July 2017. The data from DBRH- HIV-+ patients enrolled in ART with CD4+ cell count approximately and body weight of patients at every visit were taken. Statistical results at the $5 \%$ level.

Results: This study was on interest in finding and on exploring the progression $\mathrm{CD}^{+}$and body weight through time of HIV-+ under ART.

Conclusion: At baseline $\mathrm{CD}^{+}$values ranging from 11 to 1764 (Mean=53.43, SD= 287.31). The mean CD4 $/ \mathrm{HIV}$ patients have fluctuated that is increases and decreases in their follow-ups. The maximum mean CD4+ reached at time point six with a mean value of 397.37. The number of observations was decreased until the final time point. CD4 ${ }^{+}$score was measured for eight repeatedly time points in months with values ranging from 11 to 2171 (mean 254.51, SD 218.15), where low count values correspond to a patient is at risk, while high scores correspond to a better health condition of the patient. The Q-Q plot and box plots of square root transformation of the data were appropriated.
\end{abstract}

Key-words: ART, CD4 count, HIV/AIDS, Longitudinal data, Missing data

\section{INTRODUCTION}

The human immunodeficiency virus (HIV) and acquired immune deficiency syndrome (AIDS) have become one of the major health problems in all cover worlds ${ }^{[1]}$. HIV/AIDS is one of the serious human health problems in the developing countries specially, in Sub-Saharan Africa, including Ethiopia. These countries have been affected by the epidemic with a high prevalence.

\section{How to cite this article}

Muralidharan AR, Admasu A. Effects of ART on CD4 Count and Body Weight in HIV/AIDS Patients using Longitudinal Analysis in the Case of Debre Berhan Referral Hospital. SSR Inst. Int. J. Life Sci., 2020; 6(4): 2623-2639.

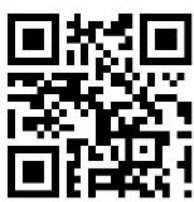

Access this article online https://iijls.com/
HIV is a virus that causes AIDS by reducing a person's immunity to protect infection. HIV is a human virus, which attacks human beings only ${ }^{[2,3]}$.

The disease is widely spread in low and middle-income developing countries, such as South Africa and other sub-Saharan African countries ${ }^{[4]}$. For decades, scientists and humanitarian groups are working on pharmaceutical medicine for HIV/AIDS, but still not possible. The possible way, which is better than none is treating patients through clinical treatment called ART.

Currently, the only available treatment for HIV/AIDS is ART. However, the introduction of ART brought dramatic changes to the lives of people (UNAIDS/ WHO). People living with HIV have started to live longer and AIDSrelated deaths have also been declining because of the availability of the ART programmed ${ }^{[5]}$. Globally, 38.8 million people were living with HIV, 2.5 million new HIV 
infections, and 1.2 million HIV/AIDS (acquired immunodeficiency syndrome) deaths in $2015^{[6]}$.

Antiretroviral drug is introduced in Ethiopia 2003 to reduce HIV-related morbidity and mortality, improve the quality of life of people with HIV (FHAPCO and FMOH). In October 2005, the Ministry of Health of Ethiopia announced that it would provide free antiretroviral drugs in public hospitals based solely upon an individual's clinical eligibility.

Ethiopia is currently working on the accessibility of antiretroviral drugs through decentralizing HIV care and treatment services to primary health care, (FHAPCO and $\mathrm{FMOH}$ ). Globally, the principal route of transmission is unprotected heterosexual intercourse $(>75 \%)$. This accounts for the increasing number of women being accepted worldwide. Homosexual intercourse is the second commonest route of transmission ${ }^{[7]}$.

HIV medicines help people with HIV live longer, healthier lives. Sometimes HIV medicines can also cause side effects. Most side effects from HIV medicines are manageable, but a few can be serious. Overall, the benefits of HIV medicines far outweigh the risk of side effects. In addition, many newer HIV medicines have fewer side effects than older HIV medicines. As HIV treatment options continue to improve, people are less likely to experience side effects from their HIV medicines [8].

A study has showed that the HAART regimen conferred clinical improvement on patients involved as the CD4 count and weight gain represent good indices of response to therapy. Weight loss is associated with significant morbidity and mortality in population living with HIV/AIDS ${ }^{[8]}$. In many medical cases more than one clinical outcome are measured longitudinally at the same time on the same subject where these measured clinical outcomes are correlated ${ }^{[9,10]}$. Since they are highly related changes in either often affects changes in the other. In such cases, the univariate longitudinal analysis does not take into account correlation between observations on different response variables at each time points ${ }^{[11-13]}$. Besides this knowing how the evolution of one is related to the evolution of the other, as well as how the association changes or evolves over time is difficult from univariate longitudinal analysis. The longitudinal model can be easily extended to include multiple response variables by further stacking the data $[14,15]$.
Statement of the Problem- In many medical cases more than one clinical outcome was measured longitudinally at the same time on the same subject, where these measured clinical outcomes were correlated ${ }^{[16]}$. We observed two or more longitudinal outcomes that need joint modeling of the response variables to identify predictors that accepted jointly. This study was aimed at determining the specific effect of ART on CD4 Count and body weight on HIV/AIDS patients jointly over time.

\section{MATERIALS AND METHODS}

A retrospective longitudinal study for 4 years carried out from the data of patients initiated to ART, starting from July 2014 to July 2017. The data from DBRH- HIV-+ patients enrolled in ART with $\mathrm{CD}^{+}$cell count approximately and body weight of patients at every visit were taken. Statistical results at the $5 \%$ level.

The data used in this study was collected from Debre Berhan Referral Hospital, Debre Berhan, Ethiopia to determine the impact of $\mathrm{ART}$ on $\mathrm{CD}^{+}$cell counts and body weight status in HIV/AIDS patients) during the period 2013 to 2017. Debre Berhan Referral Hospital is found in Debre Berhan town, North Shoa administrative zone, $695 \mathrm{~km}$ away from Bahir Dar, the Capital City of the Amhara National Regional State, and $130 \mathrm{~km}$ North East of Addis Ababa, on the highway to Dessie. It is one of the Zonal Hospital of Amhara Regional State.

In this study, the data was found from the patients chart. In which, the data was taken from 2013-2017. The longitudinal response variable $\mathrm{CD} 4^{+}$cell counts per $\mathrm{mm}^{3}$ of blood and body weight were taken approximately every 6 months. As HIV infection progresses, most people experience a gradual decrease in the number of cells in their blood called CD4+, T cells and their body weight. The data set was found from the longitudinal data individuals were extracted from the patient's chart, which contains epidemiological, laboratory and clinical information of all HIV patients under ART follow-up including a detailed ART history. Patients with at least one time CD4+ count measurements and those, who started first line regimens, were included.

Statistical Analysis- To address the objectives of the study, in this section results obtained from separate analysis of the two response variables $\mathrm{CD}^{+}$cell count and body weight of patients are employed. This article is mainly focused on exploring the progression of $\mathrm{CD} 4^{+}$cell count and body weight through time of HIV-positive 
patients, who were under ART. We would begin by exploring descriptive statistics and graphs to illustrate the relationship between predictors and the two longitudinal outcomes.

\section{RESULTS}

\section{Study Variables}

Response variables- The two outcome variables considered for this study was longitudinal CD4 count

Table 1: List of covariates used in this study measurement and weight of HIV/AIDS patients, which is measured in $\mathrm{kg}$. The CD4 cell counts per $\mathrm{ml}^{3}$ of blood, which is considered as a biomarker was measured approximately within 6 months interval whereas the weight of the patients were measured at each patient visit.

\begin{tabular}{|c|c|c|c|}
\hline No. & Variable Name & Description & Label \\
\hline 1 & Gender & Gender of patient & $0=$ Female, $1=$ Male \\
\hline 2 & Age & Age of patient at baseline & Continuous \\
\hline 3 & Marital status & $\begin{array}{l}\text { Marital status of the patient at the } \\
\text { baseline }\end{array}$ & $0=$ Single, $1=$ Married and $2=0$ thers \\
\hline 4 & Educational status & $\begin{array}{l}\text { Educational status of patients at } \\
\text { baseline }\end{array}$ & $\begin{array}{c}0=\text { Not educated, } 1=\text { Primary, } \\
2=\text { Secondary, } 3=\text { Tertiary }\end{array}$ \\
\hline 5 & Residence & Residence of patients at baseline & $0=$ Rural, $1=$ Urban \\
\hline 6 & Bassline $\mathrm{CD} 4^{+}$ & Bassline CD4+ count of patients & Continuous \\
\hline 7 & BMI & $\begin{array}{c}\text { Body mass index of patients at } \\
\text { baseline in } \mathrm{kg} / \mathrm{m}^{2}\end{array}$ & Continuous \\
\hline 8 & Time & Time in months & In months \\
\hline 9 & WHO & WHO stage at baseline & $\begin{array}{l}\text { 0= Stage I, 1= Stage II, } \\
\text { 2= Stage III and 3= Stage IV }\end{array}$ \\
\hline 10 & $\mathrm{Ol}$ & $\begin{array}{c}\text { Opportunistic Infection status } \\
\text { patients at baseline }\end{array}$ & $0=$ No, $1=$ Yes \\
\hline 11 & Regimen class & $\begin{array}{c}\text { Regimen class of a patient at } \\
\text { baseline }\end{array}$ & $\begin{array}{c}\text { 0= AZT-3TC-EFV , 1= AZT-3TC-NVP, } \\
\begin{array}{c}\text { 2= TDF-3TC-NVP, 3= TDF-3TC-EFV and } \\
\text { 4= Others }\end{array}\end{array}$ \\
\hline 12 & ART duration & Number of years on ART use & Years 1,2,3 and above \\
\hline 13 & Functional status & Functional status of a patient & $\begin{array}{c}0=\text { Working }, 1=\text { Ambulatory and } \\
2=\text { Bed redden }\end{array}$ \\
\hline
\end{tabular}

In this sub-section, the descriptive statistics of HIVpositive patients enrolled in Art case unit of Debre Berhan Referal Hospital during the period September 1, 2014 to July 30, 2017, in Debre Berhan, Ethiopia was carried out. The total number of patients included in this study is 536. The descriptive statistics of continuous and categorical variables of HIV positive patients, which are included under this study, will be presented.

Table 2: Descriptive Statistics of $\mathrm{CD}^{+}$count score by time point

\begin{tabular}{ccccccccc}
\hline Time & Baseline & $\mathbf{1}$ & $\mathbf{2}$ & $\mathbf{3}$ & $\mathbf{4}$ & $\mathbf{5}$ & $\mathbf{6}$ & $\mathbf{7}$ \\
\hline $\mathrm{N}$ & 536 & 536 & 536 & 535 & 533 & 531 & 530 & 527 \\
Mean & 553.43 & 541.31 & 553.16 & 555.26 & 557.63 & 579.23 & 567.72 & 576.11
\end{tabular}




$$
\text { SD }
$$

287.31

Min

$$
11
$$

Max
251.54

8

1316
253.56

6

1306
245.53

6

1304
243.63

\begin{abstract}
7
\end{abstract}
1394
255.78

8
266.03

5

1354
267.14

7

\section{SD= Standard deviation}

From Table 2, at baseline the patients $\mathrm{CD} 4^{+}$cell count with values ranging from 11 to 1764 (mean $=553.43$, standard deviation $(S D)=287.31)$. The mean $\mathrm{CD}^{+}$cell count of HIV positive patients increases with an increasing rate until time point four then decreases from time point four to time point five and also increase from time point five to six then increase until the final time point seven five ${ }^{[17]}$. The maximum mean $\mathrm{CD}^{+}$cell count reached at time point six with a mean value of 397.37. The number of observations is decreased until to the final time point. $C D 4^{+}$cell count score was measured for eight repeatedly time points (at baseline: before they are under ART, Time 1, Time 2, Time 3, Time 4, Time 5, Time 6 , and Time 7) (months) with values ranging from 11 to 2171 (mean $=254.51$, standard deviation $(S D)= \pm 218.15$ ), where low count values correspond to a patient is at risk, while high scores correspond to a better health condition of the patient. The patients were measured their $\mathrm{CD4}^{+}$ cell count values at the baseline, before they are subject to under ART. ART is not free from AIDS but it greatly improves the health condition of HIV/AIDS patients. Missing is considerably increasing through time is gone.

Table 3: Descriptive Statistics of body weight score by time point

\begin{tabular}{ccccccccc}
\hline Time & Baseline & $\mathbf{1}$ & $\mathbf{2}$ & $\mathbf{3}$ & $\mathbf{4}$ & $\mathbf{5}$ & $\mathbf{6}$ & $\mathbf{7}$ \\
\hline $\mathbf{N}$ & 536 & 536 & 536 & 533 & 506 & 495 & 473 & 467 \\
Mean & 52.28 & 51.24 & 51.68 & 52.18 & 52.99 & 52.03 & 53.19 & 52.96 \\
SD & 10.35 & 10.69 & 10.21 & 10.48 & 10.58 & 10.45 & 10.17 & 10.15 \\
Min & 18 & 16 & 17 & 17 & 16 & 17 & 18 & 17 \\
Max & 88 & 89 & 88 & 87 & 87 & 87 & 87 & 89 \\
\hline
\end{tabular}

\section{$\mathrm{SD}=$ Standard deviation}

Table 3, the mean value of body weight of HIV positive patient's shows increases and decreases when the time increases. The mean of weight increase from time point one up to time point six then decreases from time point six to time point seven. The maximum mean of body weight reached at time point with a mean value of 53.16. The numbers of observations are constant up to time point two and it is decreased from time point three up to the final time point. Body weight score was measured for eight repeatedly time points (at baseline: before they are under ART, Time 1, Time 2, Time 3, Time 4, Time 5, Time 6 and Time 7) (months), with values ranging from 13 to 89 (mean $=52.60$, standard deviation $(S D)= \pm 11.07$ ), where low count values correspond to a patient is at risk, while high scores correspond to a better health condition of the patient. The patients have measured their bodyweight values at the baseline, before they are subject to under ART and continuously at the six month follow-up. Missing considerably increasing through time is gone.

Two continuous and nine categorical baseline covariates are included in this study analysis. The patients have measured their age and BMI at baseline before they are under ART. The means of these continuous baseline covariates age and BMI are 34.01 years, and $21.57 \mathrm{~kg} / \mathrm{m}^{2}$ with standard deviations 10.32 years and $3.9 \mathrm{~kg} / \mathrm{m}^{2}$, respectively. These two continuous covariates are standardized to have a mean 0 and variance 1 in the remainder of this study for the sake of parameter convergence. As such, their coefficients in the regression models represent the effect per 1-SD change. The minimum values of the baseline continuous covariates are 16 and 12.74, respectively and the maximum values are 70 and 33.78 , respectively for age and BMI. 
Table 4: Descriptive Statistics of baseline continuous covariates

\begin{tabular}{llllll}
\hline Variable & N & Mean & SD & Min & Max \\
\hline Age & 536 & 34.01 & 10.32 & 16 & 70 \\
BMI & 536 & 21.57 & 3.9 & 12.74 & 33.78 \\
\hline
\end{tabular}

$\mathrm{SD}=$ Standard deviation

From Table 4, the progression of $\mathrm{CD}^{+}$cell counts and weight also determined by factors such as sexa binary indicator; Marital status: single, married and others (divorced/widowed). functional status: working, ambulatory and bedridden; WHO stage: Stage I, Stage II,

\section{Stage}

III and Stage IV; ART regimen class: AZT-3TC-EFV, AZT3TC-NVP, TDF-3TC-NVP, TDF-3TC-EFV and Other (some other ART treatments); Residence: rural and urban; Educational status: not educated, primary, secondary and tertiary; Opportunistic Infection; no and yes (if any); $A R T$ in years they take (duration of ART treatment); less than two years, two up to three years and above three years. The descriptive statistics of these categorical variables taken at baseline are presented. The number of categorical variables (such as- Sex of the patient, marital status of the patient, educational status, residence, regimen class of the patient, functional status of the patient, WHO clinical stage of the patient, ART in years and opportunistic infection) across follow up time points are not different ${ }^{[18]}$.

Table 5: Frequencies and Percentages for baseline categorical covariates

\begin{tabular}{ccc}
\hline Characteristics & Category & Total (\%) \\
\hline Sex of patients & Female & $315(58.77)$ \\
& Male & $221(41.23)$ \\
Marital status of & Single & $159(29.66)$ \\
patient & Married & $260(21.83)$ \\
& Other & $117(32.65)$ \\
Educational status & Pot educated & $109(20.34)$ \\
of patient & Secondary & $117(21.83)$ \\
& Tertiary & $45(8.40)$ \\
Residence of & Rural & $114(21.27)$ \\
patient & Urban & $522(78.73)$
\end{tabular}

\begin{tabular}{|c|c|c|}
\hline \multirow{4}{*}{$\begin{array}{l}\text { WHO staging at } \\
\text { ART initiation at } \\
\text { baseline }\end{array}$} & Stage I & 195 (36.38) \\
\hline & Stage II & $148(27.61)$ \\
\hline & Stage III & 115 (21.27) \\
\hline & Stage IV & 79 (24.74) \\
\hline \multirow{4}{*}{$\begin{array}{l}\text { Opportunistic } \\
\text { Infection status } \\
\text { patient }\end{array}$} & NO & $154(28.73)$ \\
\hline & YES & $382(71.27)$ \\
\hline & AZT-3TC-EFV & $128(23.88)$ \\
\hline & AZT-3TC-NVP & $132(24.63)$ \\
\hline \multirow{4}{*}{$\begin{array}{l}\text { Regimen class of a } \\
\text { patient }\end{array}$} & TDF-3TC-EFV & 139 (25.93) \\
\hline & TDF-3TC-NVP & $129(24.07)$ \\
\hline & OTHER & $8(1.49)$ \\
\hline & $\begin{array}{c}\text { Less than two } \\
\text { year }\end{array}$ & $95(17.72)$ \\
\hline \multirow[t]{3}{*}{$\begin{array}{c}\text { Number of years } \\
\text { on ART }\end{array}$} & $\begin{array}{c}\text { Two up to three } \\
\text { year }\end{array}$ & $174(32.46)$ \\
\hline & $\begin{array}{c}\text { Above three } \\
\text { year }\end{array}$ & $267(49.81)$ \\
\hline & Working & 267 (49.81) \\
\hline \multirow{2}{*}{$\begin{array}{l}\text { Functional status } \\
\text { of a patient }\end{array}$} & Ambulatory and & $161(30.04)$ \\
\hline & Bed redden & $108(20.15)$ \\
\hline Total Observation & $\mathrm{N}$ & 536 \\
\hline
\end{tabular}

Table 5 shows the number of female patients was greater than the number of male patients (i.e., $315(58.77 \%)$ female and 221(41.23\%) male). About $109(20.34 \%)$ of the patients have not educated, $265(49.44 \%)$ are in primary level, $117(21.83 \%)$ and $45(8.40 \%)$ are fulfilled secondary and tertiary levels respectively. HIV-positive patients, which are under ART $159(26.66 \%)$ single, 260(48.51\%) married and the remaining $117(21.83 \%)$ have divorced/widowed marital status. About $95(17.72 \%)$ of the patients are take ART less than two years,174(32.46\%) are take about two up to three years and the left 267(49.81) are take above three years long. According to ART regimen class 128(23.88) are take the treatment of AZT-3TC-EFV, 132(24.63\%) were take AZT-3TC-NVP, 139(25.93\%) are take TDF-3TC-EFV, 117(21.83\%) are take TDF-3TC-NVP and the only $45(8.40 \%)$ were take other treatment of ART (duration of ART individual taken). According to residence of individuals $114(21.27 \%)$ were from rural area and $422(78.73 \%)$ are from urban areas. 
When, we see the functional status of patients $267(49.81 \%$ ) are working (able to do their day to day activities like farming, harvesting, office work and others) only $161(30.04 \%)$ are ambulatory and $108(20.15 \%)$ were bedridden. About $195(36.38 \%)$ of the patients have started ART treatment with initial WHO-clinical stage of stage-I, and the remaining $148(27.61 \%), 115(21.27 \%)$, and $79(24.74 \%)$ are stage-II, stage-III and stage-IV, respectively. The only $154(28.73 \%)$ of the patients have not an opportunistic infection and 382(71.27) have one or more opportunistic infection. All these percentages were the same for all time points (i.e. there were no different measurements taken through follow up time points).

\section{Analysis of CD4 cell count and body weight distribution} of $\mathrm{CD}^{+}$Count Data- To analyze the longitudinal pattern of $\mathrm{CD}^{+}$count data, first should check the normality assumptions

of the data is necessary. The more formal approach was to conduct a statistical test of the assumption of normality (as it applies to the shape of the sample). Normality test is most-often done using either the Kolmogorov-Smirnov or the Shapiro-Wilk test, which are both non-parametric tests that allow one to check the shape of a sample data against a variety of known, popular shapes, including the normal and using plots like q-q plot, histograms and box plots of the sample data. Most of the time count data was better approximated by a normal distribution when the number of counts becomes large enough. To normalize the data the square root transformed and the logarithmic transformed were carried out. For this study, actual $\mathrm{CD}^{+}$count, Square root transformed and logarithmic of $\mathrm{CD}^{+}$count, for overall measurements q-q plots were presented on Fig. 1(b) and Shapiro-wilk test in Table 6 presented for checking the normality assumption of the data. From the Shapiro-wilk test of normality in Table 1, we had found that the actual $\mathrm{CD}^{+}$count is not normal at all-time points as the test shows there was significance deviation from normality. From the logarithmic transformed CD4 ${ }^{+}$ count Shapiro-wilk test we have found only at time point 5 was normality fulfilled, but in other time points there was significance deviation from normality. But, the test approves normality of square root transformed CD4 ${ }^{+}$ count at all-time points except at time four and time five. This coincides with Fig. 1, which takes the q-q plot of the overall data suggesting square root transformation of the data to normality and detail of the q-q plots by time are depicted in Fig. 1 on the appendix.

Table 6: Shapiro-Wilk tests of Normality

\begin{tabular}{cccccccccc}
\hline \multirow{2}{*}{ Time } & \multicolumn{3}{c}{ Actual CD4 ${ }^{+}$count } & \multicolumn{3}{c}{ Square root CD4 ${ }^{+}$count } & \multicolumn{2}{c}{ Logarithm of CD4 ${ }^{+}$count } \\
\cline { 2 - 10 } & Statistic & Df & Sig. & Statistic & Df & Sig. & Statistic & Df & Sig. \\
\hline $\mathbf{0}$ & .964 & 536 & .000 & .075 & 536 & 0.061 & .927 & 536 & .021 \\
$\mathbf{1}$ & .986 & 536 & .000 & .066 & 536 & 0.098 & .912 & 536 & .001 \\
$\mathbf{2}$ & .984 & 536 & .000 & .056 & 536 & 0.121 & .901 & 536 & .000 \\
$\mathbf{3}$ & .986 & 536 & .000 & .050 & 536 & 0.058 & .995 & 536 & .000 \\
$\mathbf{4}$ & .988 & 534 & .000 & .070 & 534 & 0.029 & .923 & 534 & .000 \\
$\mathbf{5}$ & .991 & 532 & .003 & .065 & 532 & 0.039 & .923 & 532 & .062 \\
$\mathbf{6}$ & .983 & 531 & .000 & .071 & 531 & 0.069 & .927 & 531 & .040 \\
$\mathbf{7}$ & .986 & 528 & .000 & .079 & 528 & 0.034 & .931 & 528 & .005 \\
\hline
\end{tabular}



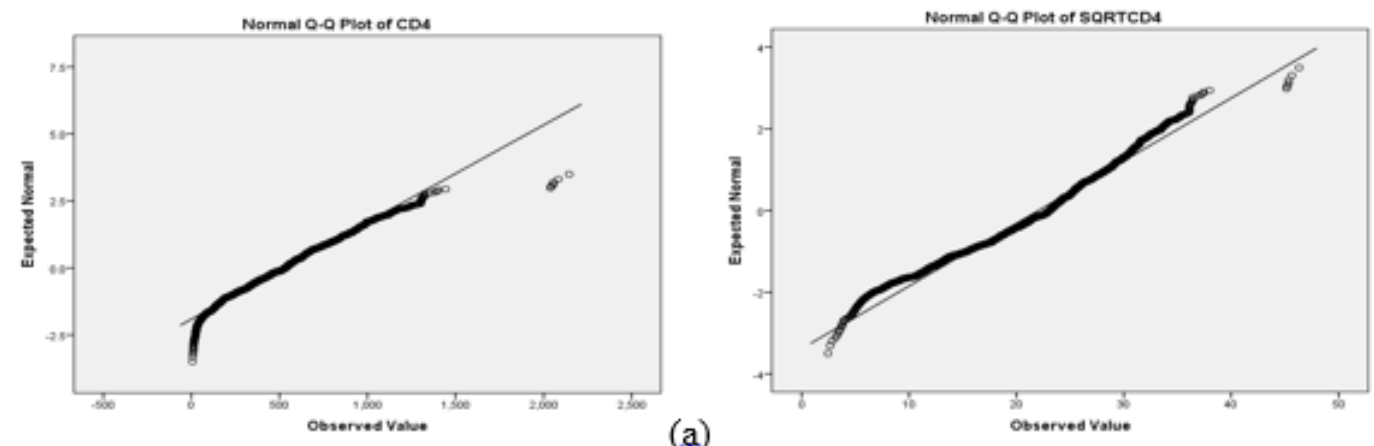

(a)
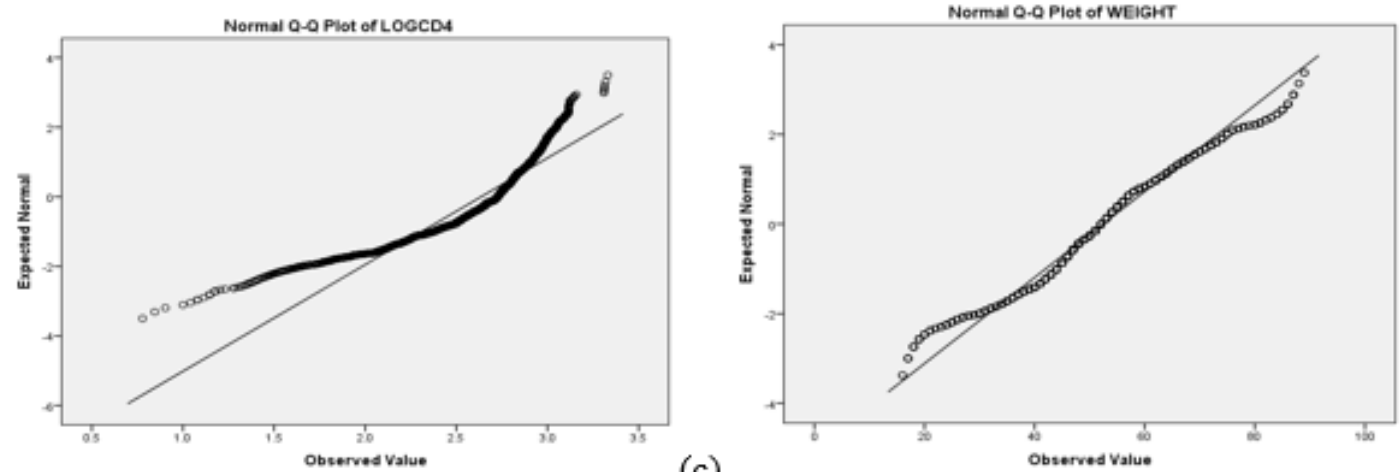

(c)

Fig. 1: Normal Q-Q plot and box plot of $C D 4^{+}$cell count: $(a, d)$ actual $C D 4^{+},(b, f)$ squrt $C D 4^{+}$and $(c, e) \log$ of $C D 4^{+}$

The Normal q-q plots and Box plots in Fig. 1 showed that the outlying observations were minimized considerably in the square root transformed $\mathrm{CD}^{+}$count Fig. 1(f) than logarithm transformed and actual $\mathrm{CD}^{+}$counts of patients. Hence, the $\mathrm{Q}-\mathrm{Q}$ plot and box plots Figure suggests square root transformation of the data is appropriate.

Distribution of Bodyweight Data- In any data analysis, before directly going to the analysis part firstly the assumptions of the data must be checked. In our body weight data Shapiro-wilk test and q-q plots depicted in Table 7 and Fig. 2; respectively were used for checking the normality of the data. In Table 2 and Fig. 2, we found that the actual body weight was normal at time points 0 (baseline time), 1, 2, 3, 5, 6 and it was not normal at time point 4 and the final time point 7 as the test showed significant deviation from normality. This coincides with Fig. 2, which takes the q-q plot of the overall data suggesting to normality and detail of the $q-q$ plots by time are depicted in Fig. 2.
Table 7: Shapiro-Wilk tests of Normality for body weight

\begin{tabular}{cccc}
\hline \multirow{2}{*}{ Time } & \multicolumn{3}{c}{ Shapiro-Wilk } \\
\cline { 2 - 4 } & Statistic & Df & Sig. \\
\hline $\mathbf{0}$ & .956 & 536 & .093 \\
$\mathbf{1}$ & .963 & 536 & .452 \\
$\mathbf{2}$ & .952 & 536 & .621 \\
$\mathbf{3}$ & .974 & 533 & .051 \\
$\mathbf{4}$ & .979 & 506 & .034 \\
$\mathbf{5}$ & .976 & 495 & .059 \\
$\mathbf{6}$ & .969 & 473 & .072 \\
$\mathbf{7}$ & .995 & 467 & .018 \\
\hline
\end{tabular}
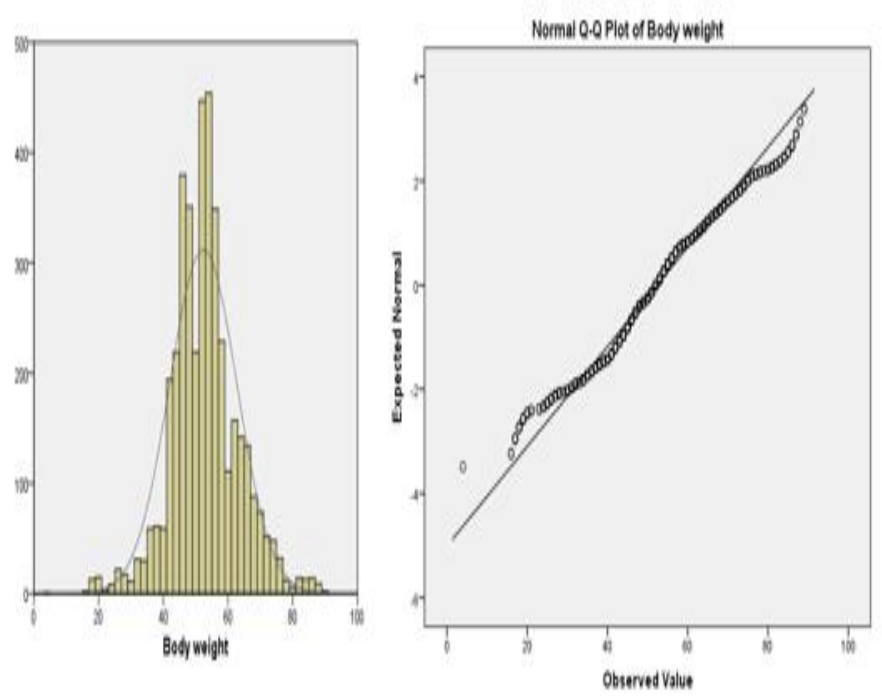

Fig. 2: Histogram and Normal Q-Q Plot of $C D 4^{+}$cell count 


\section{Exploratory data analysis}

Exploratory data analysis separately for $\mathrm{CD}^{+}$count and Bodyweight- This study presents as an introductory for the main research interest of the longitudinal data analysis. Profile plots of $\mathrm{CD}^{+}$counts and body weight of HIV/AIDS patients from DBRH for our study by exploring individual profiles, mean profiles, the variance and correlation structure plots will be presented. These profile plots help as an illustrated introductory for the statistical data analysis of the bivariate longitudinal data.

\section{Exploring Individual Profiles of $\mathrm{CD}^{+}$count with} categorical covariates- Fig. 2(a) depicts the individual profile plot of $\sqrt{C D 4+\text { counts }}$ of HIV infected patients included in this study. It is the plot of $\sqrt{C D 4+\text { counts }}$ of each patient over time. The plot provides some information on between patients $\sqrt{C D 4+\text { counts }}$ variability and illustrates that there was change in patients' $\sqrt{C D 4+\text { counts }}$ over time. Some individuals have erratic $\sqrt{C D 4+\text { counts }}$ and others have a slowly increasing $\sqrt{C D 4+\text { counts }}$ over time. As one could easily see from the graph, there is considerably large difference in the intercepts of individual trajectories.
Similarly, some trajectories were steeper while others were almost horizontal, indicating the possible variability in the slope of $\sqrt{C D 4+\text { counts. Therefore, }}$ because of the variability in the intercept and slope of trajectories, using a linear mixed model could fit the data very well.

Fig. 2(b) depicts the individual profile plot of $\sqrt{C D 4+\text { counts }}$ of HIV infected patients included in this study. It is the plot of $\sqrt{C D 4+\text { counts }}$ of each patient over time. The plot provides some information on between patients $\sqrt{C D 4+\text { counts }}$ variability and illustrate that there is a change in patients' $\sqrt{C D 4+\text { counts }}$ over time. Some individuals have erratic $\sqrt{C D 4+\text { counts }}$ and others have a slowly increasing $\sqrt{C D 4+\text { counts }}$ over time. As one could easily see from the graph, there is considerably large difference in the intercepts of individual trajectories.

Similarly, some trajectories were steeper while others were almost horizontal, indicating the possible variability

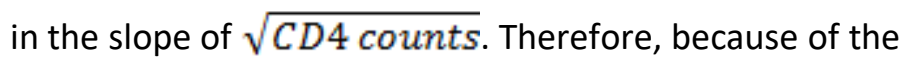
variability in the intercept and slope of trajectories, using a linear mixed model could fit the data very well.

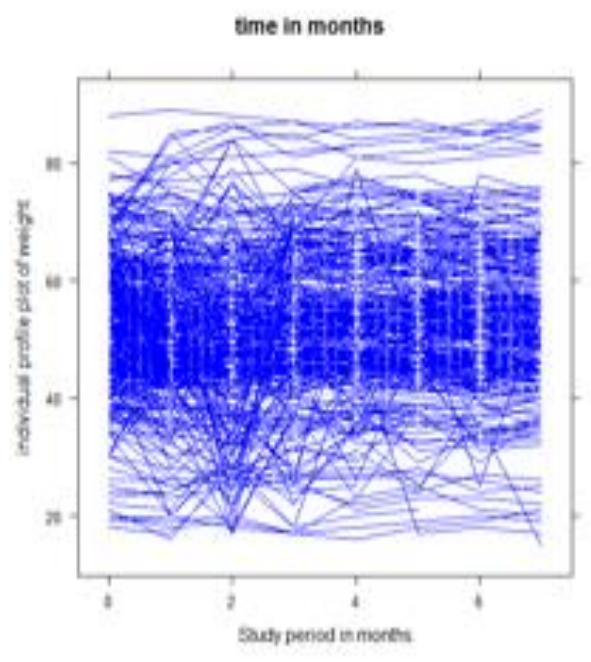

(a)
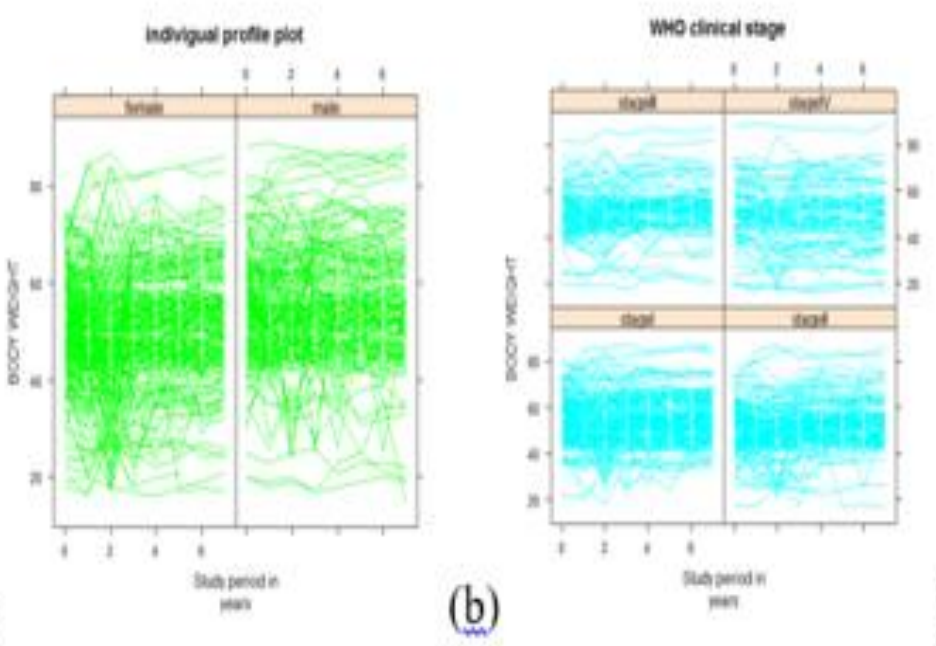

(c)

Fig. 3: Individual profile plot of square root CD4 count $(A)$, sex of patients(B), educational status(C)

The individual profile plot of $\sqrt{C D 4+\text { counts }}$ for both male and female groups is displayed in Fig. 3(B). As could be seen from the Figure, it seems that there is high within variation in both female patients and male patients. The between patients variation is high at the center of the study time as compared with at a baseline and end of the study for both groups.
Some patients have erratic evolution of $\sqrt{C D 4+\text { counts }}$ over time on both groups.

In Fig. 3(C) for the four educational status subgroups, the profile plot show there is some variability at baseline and also high variability through time. It indicates that the need for random intercept, to correct the fact that, patients who have different educational status started 
differently at different baseline $\sqrt{C D 4+\text { counts }}$ and random slope to manage the time progress variability. Some patients have erratic evolution of $\sqrt{C D 4+\text { counts }}$ over time on all subgroups groups. The cross over in the marital status subgroups may shows there is a time by marital status interaction.

From Fig. 3(C) for the four WHO-clinical stage subgroups, the profile shows there are some variability at baseline and also more variability through time. It indicates that the need for random intercept, to correct the fact that, patients, who have different WHO-clinical stages started differently at different baseline $\sqrt{C D 4+\text { counts }}$ and random slope to manage the time progress variability.
The cross over in the WHO clinical stage subgroups may show there is a time by WHO-clinical stage interaction.

\section{Mean profile plot of $\sqrt{C D 4+\text { counts }}$ and categorical}

covariates over time- The overall mean profile plot of $\sqrt{C D 4+\text { counts }}$ shows somehow a linear increasing pattern of $\sqrt{C D 4+\text { counts }}$ over time (Fig. 4), which suggested that a linear time effect is reasonable. The mean $\sqrt{C D 4+\text { counts }}$ decreases in a high rate from baseline till the $6^{\text {th }}$ month and then it starts to increase in high rate from $6^{\text {th }}-30^{\text {th }}$ month and decreases at month 30 then it starts to increase after the $30^{\text {th }}$ month.
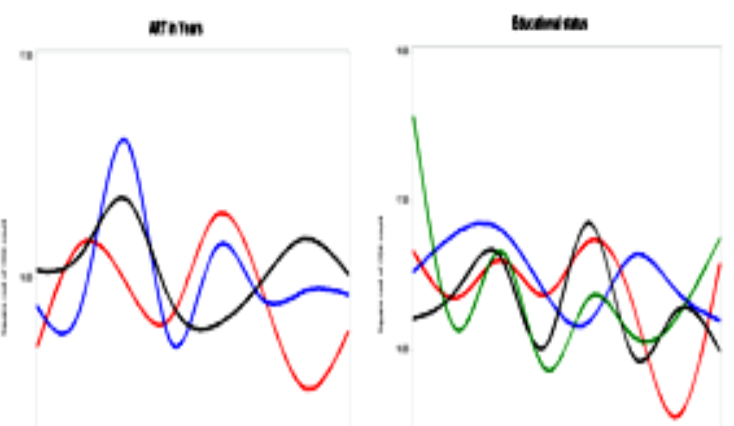

(a)

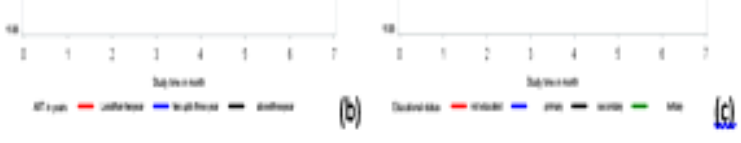

Fig. 4: Mean Profile Plot for sqrtCD4 ${ }^{+}$HIV/AIDS Patients (a), duration of ART (b) and educational status(c)

From Fig. 4(c) for the four educational status subgroups, the mean profile plot shows there is high variability at baseline and also high variability through time and goes to constant at the end of the study. It indicates that the need for random intercept, to correct the fact that, patients, who have different educational status started differently at different baseline $\sqrt{C D 4^{+} \text {counts }}$ and random slope to manage the time progress variability. Some patients have erratic evolution of $\sqrt{C D 4^{+} \text {counts }}$ overtime at all groups. The cross over in the educational status subgroups may shows there is a time by educational status interaction.

Fig. 4(b) for the ART in years how many patients they take subgroups, the mean profiles shows us there is variability in $\sqrt{C D 4^{+} \text {counts }}$ among the three subgroups. In all of the subgroups there is fluctuation in the $\sqrt{C D 4^{+} \text {counts }}$ overtime. There was also large within- group variability in $\sqrt{C D 4^{+} \text {counts }}$ and large between group variability. The figure indicates that the need for random intercept, to correct the fact that, patients started differently at different baseline $\sqrt{C D 4^{+} \text {counts }}$ and random slope to manage the between patient variability. The difference shown in the smoothed lines may indicate time by $\sqrt{C D 4^{+} \text {counts }}$ interaction. There is also seen crossover for some subgroups.

Exploring Individual Profiles of Bodyweight with categorical covariates- Fig. 5(a) depicts the individual profile plot of body weight of HIV/AIDS patients under ART included in this study. It is the plot of weight of each patient over time. The plot provides some information on between patients of weight variability and illustrate that there is change in patients' body weight over time. 
Some individuals have an erratic evaluation and others have a slowly increasing weight over time and others are constant over time. It indicates some within variability and more between variability of individuals. As one could easily see from the graph, there is considerably large difference in the intercepts of individual trajectories.

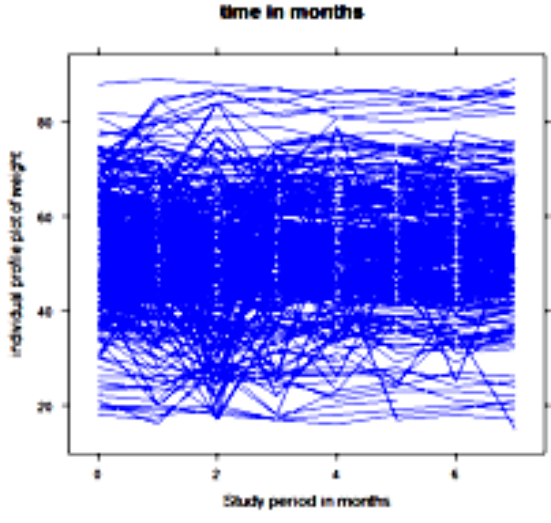

(a)

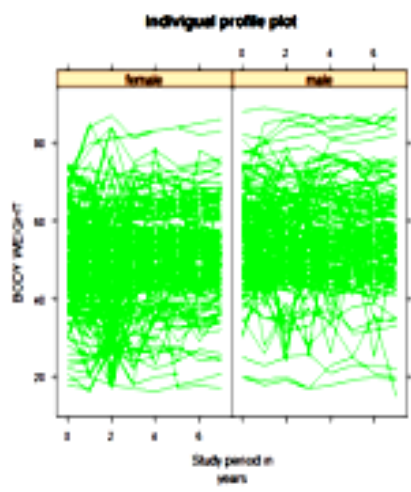

Fig. 5: Individual profile plot of body weight (a), sex of patients (b) and WHO clinical stage (c)
Similarly, some trajectories were steeper while others were almost horizontal, indicating the possible variability in the slope of body weight. Therefore, because of the variability in the intercept and slope of trajectories, using a linear mixed model could fit the data very well.
Fig. 5(b) for the sex subgroups, the individual profiles show larger between patient variability and also shows that small within patient variability in each of gender group. In both of the sex subgroups there is some within variability and more between variability overtime The figure indicates that the need for the random intercept, to correct the fact that, patients started differently at different baseline weight and random slope to manage the between patient variability.

Fig. 5(c) for the four WHO clinical stage status subgroups, the profiles shows us there was variability in body weight among the four subgroups. In all of the WHO stage subgroups signed by the physician, there is some within variability and more between variability overtime.
The figure indicates that the need for random intercept, to correct the fact that, patients started differently at different baseline weight and random slope to manage the between patient variability.

\section{Mean profile plot of body weight categorical covariates} over time- The loss smooth curve, as shown in (Fig. 6a), suggests that the average profile of body weight has a linear relationship over time. It indicates that weight of patients show as light increasing pattern, but also it decreasing at time points seven and also it indicates the linear time effects in the model.
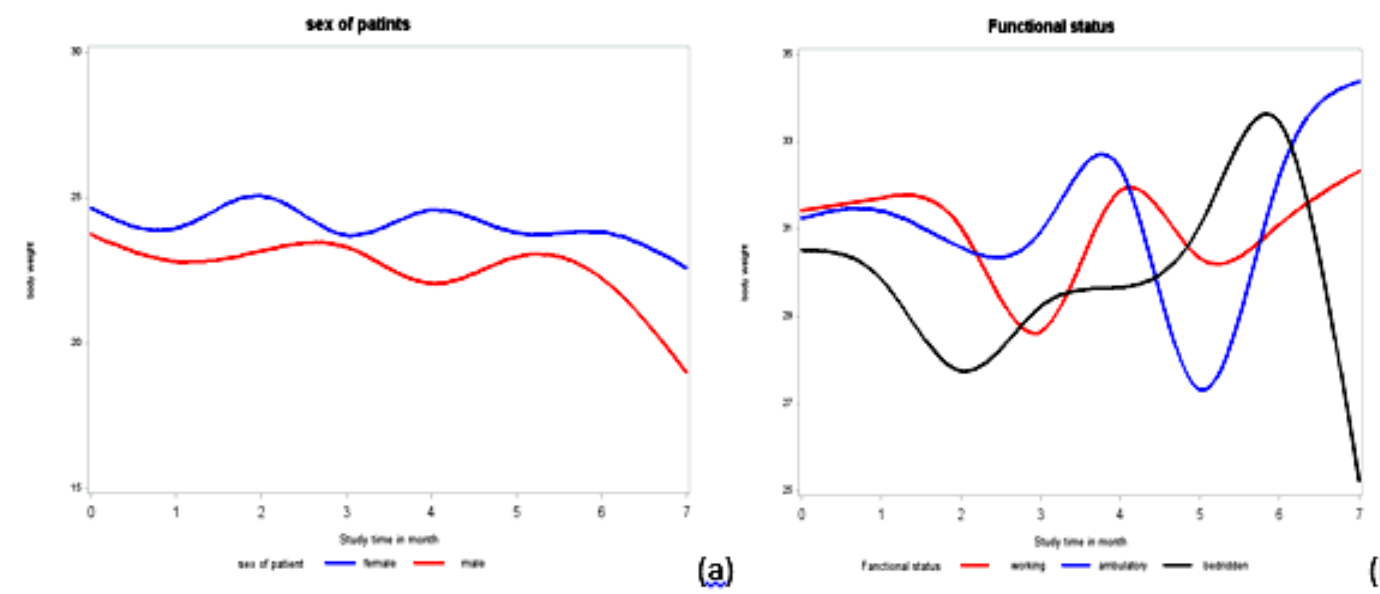

Fig. 6: Mean Profile Plot for body weight of HIV/AIDS Patients (a) sex of patients and (b) functional status 
Fig. 6(a) for the sex subgroups, the individual profiles shows larger between-group variability and also shows that small within group variability in each gender group. The mean profile shows the variability of female patients seems higher than male patients through time. It indicates that the need for random intercept, to correct the fact that, patients started differently at different baseline body weight. In addition to random intercept, there is a need for random slope to allow subjects to have different slopes and account for the unstable between subject variability at different time points. As shown from the mean profile females have higher mean of body weight until the final time but the difference is changed over time. The slope over time appears to be a bit steeper for male than for both groups, so we may expect to see a difference between male and female at last time point. We may want to include an interaction between sex and time to see if this is true.

Fig. 6(b) for the functional status subgroups, the profiles shows us there is variability in body weight of HIV/AIDS patients among the three subgroups. There is also large within group variability in body weight and large between group variability. The figure indicates that the need for random intercept, to correct the fact that, patients started differently at different baseline body weight and random slope to manage the between patient variability. The difference shown in the smoothed lines may indicate time by functional status interaction. There is also seen crossover for some subgroups.
Exploring Variance Function of $\sqrt{C D 4^{+} \text {counts }}$ and body weight of patients- The variance structure for $\sqrt{C D 4^{+} \text {counts }}$ and body weight of patients shows an irregular pattern over time (Fig. 7). The smooth variance

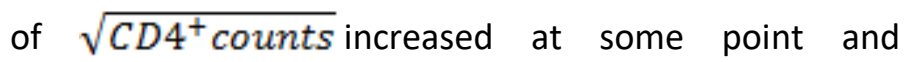
decreases at another point suggesting a non-constant variance. From Fig. 7(a), it can be observed that the variance of patient's $\sqrt{C D 4^{+} \text {counts }}$ decreases at an increasing rate until time two increases at an increasing rate to time three and then decreases with an increasing rate up to time four, increases at an increasing rate to time six and approximately constant uptime seven. This implies that, spatial variance structures would be needed in modeling of patient's $\sqrt{C D 4^{+} \text {counts }}$ over time rather than the constant one.

From Fig. 7(b), we observed that the variances of patients body weight, shows that the observed variance function, which is changing over time, this implies that the need for other random effects in addition to the random intercepts would be needed in modeling patients body weight over time. And also it shows that the variability of the observation is not constant over time. Generally, the variance of patient's $\sqrt{\mathrm{CD}^{+} \text {count }}$ and body over time fluctuates from time to time in different covariates.
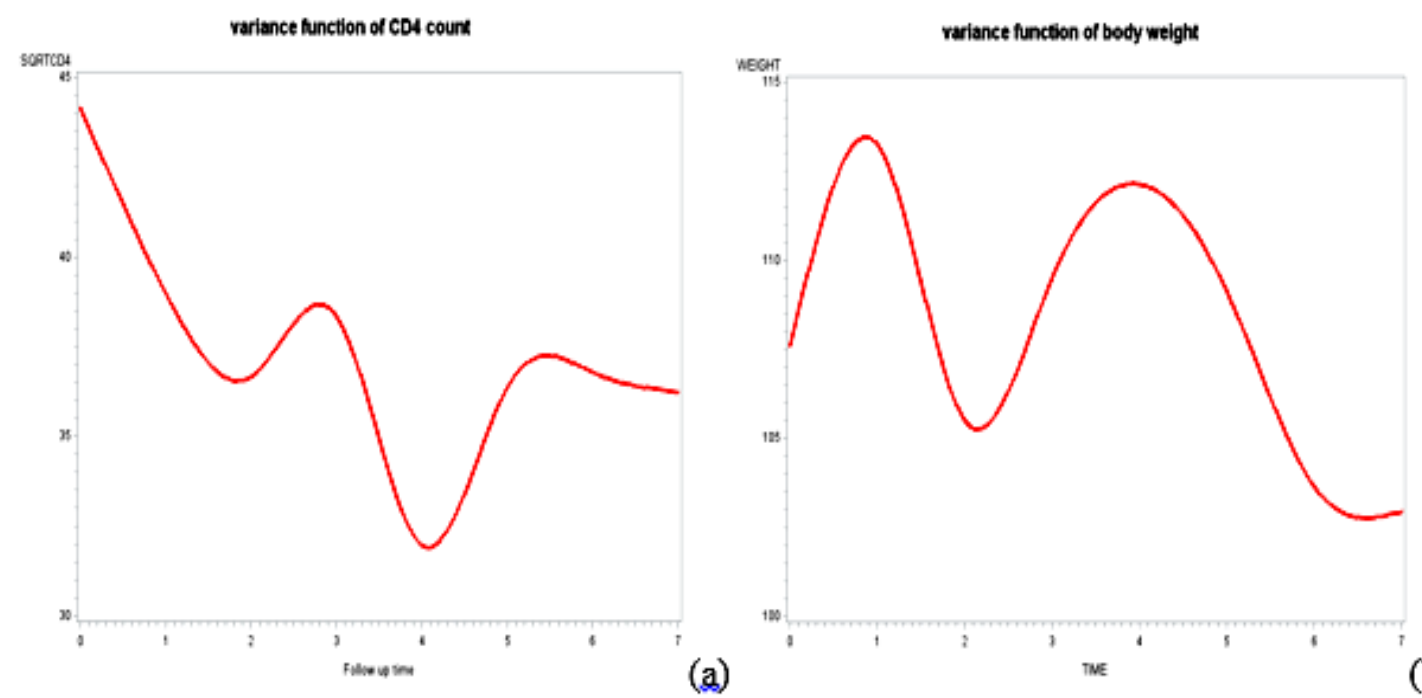

(a)

(b)

Fig. 7: Variance Function Structure of $(a) \sqrt{C D 4^{+} \text {count }}$ and (b) body weight of HIV/AIDS patients 
Exploring correlation structure and Scatter plot of Correlation matrix- From Table 4.8, the correlation matrix can be used to show the correlation between repeated

measurements. The correlation in the presence of dropouts and misingness could be computed in various ways. In this study, we used the available data for computing the correlation matrix. Moreover, we observed from the above pair wise correlation matrix can be used for exploring the correlation within repeated also we examine that the correlation between patients different at different time points. There was a strong correlation between all-time points, whereas the correlation is not constant over time. The value of the correlation matrix the correlation between time 5 and time 6 is $96 \%$ this indicates that highly correlated time points and the correlation between at baseline and time 4 was $(80.3 \%)$ are weakly correlated. This indicates that the correlation time points are not constant. $\sqrt{C D 4^{+} \text {count }}$ of patients over follow up time and

Table 8: Correlation Matrix of over Time

\begin{tabular}{|c|c|c|c|c|c|c|c|c|}
\hline & T_0 & T_1 & T_2 & T_3 & T_4 & T_5 & T_6 & T_7 \\
\hline T_0 & 1.0000 & 0.8559 & 0.8407 & 0.8363 & 0.8034 & 0.8337 & 0.8466 & 0.8216 \\
\hline T_1 & & 1.0000 & 0.9614 & 0.9332 & 0.8934 & 0.9420 & 0.9263 & 0.8865 \\
\hline T_2 & & & 1.0000 & 0.9367 & 0.9261 & 0.9525 & 0.9373 & 0.9207 \\
\hline T_3 & & & & 1.0000 & 0.9177 & 0.9412 & 0.9478 & 0.9337 \\
\hline T_4 & & & & & 1.0000 & 0.9324 & 0.9362 & 0.9168 \\
\hline T_5 & & & & & & 1.0000 & 0.9612 & 0.9202 \\
\hline T_6 & & & & & & & 1.0000 & 0.9575 \\
\hline T_7 & & & & & & & & 1.0000 \\
\hline
\end{tabular}

The correlation matrix can be used to show the correlation between repeated measurements. The correlation in the presence of dropouts and missing's could be computed in various ways. In this study, we used the available data for computing the correlation matrix. The correlation matrix shown in Table 9 revealed a positive correlation between any two repeated measurements. Moreover, we observed from the above pair wise correlation matrix can be used for exploring the correlation within repeated patients over follow up time and also we examine that the correlation between patients different at different time points. There was strong correlation between alltime points, whereas the correlation is not constant over time.
The value of the correlation matrix the correlation between time 6 and time 7 was 93.25\%, this indicated that highly correlated time points and the correlation between at baseline and time 42 was (64.3\%) were weakly correlated. This indicates that the correlation time points are not constant over all time points.

Pairwise scatter plots were used for exploring the correlation between any two repeated measurements of $\mathrm{CD}^{+}$count of patients and body weight of patients and it appears that there was a positive and linear relationship between $C D 4^{+}$counts and body weight at different time points (Fig. 8). 
Table 9: Correlation Matrix of body weight over Time

\begin{tabular}{lcccccccc}
\hline & WT_0 & WT_1 & WT_2 & WT_3 & WT_4 & WT_5 & WT_6 & WT_7 \\
\hline WT_0 & 1.0000 & 0.8102 & 0.6433 & 0.8303 & 0.7981 & 0.8501 & 0.8386 & 0.8301 \\
WT_1 & & 1.0000 & 0.7545 & 0.8855 & 0.8065 & 0.8677 & 0.8265 & 0.8072 \\
WT_2 & & 1.0000 & 0.7021 & 0.7034 & 0.7046 & 0.6966 & 0.6874 \\
WT_3 & & & 1.0000 & 0.8619 & 0.9137 & 0.8836 & 0.8873 \\
WT_4 & & & & 1.0000 & 0.8923 & 0.9149 & 0.8704 \\
WT_5 & & & & & 1.0000 & 0.9133 & 0.8995 \\
WT_6 & & & & & & & & \\
WT_7
\end{tabular}

scatter plot matrix of Square root CD4

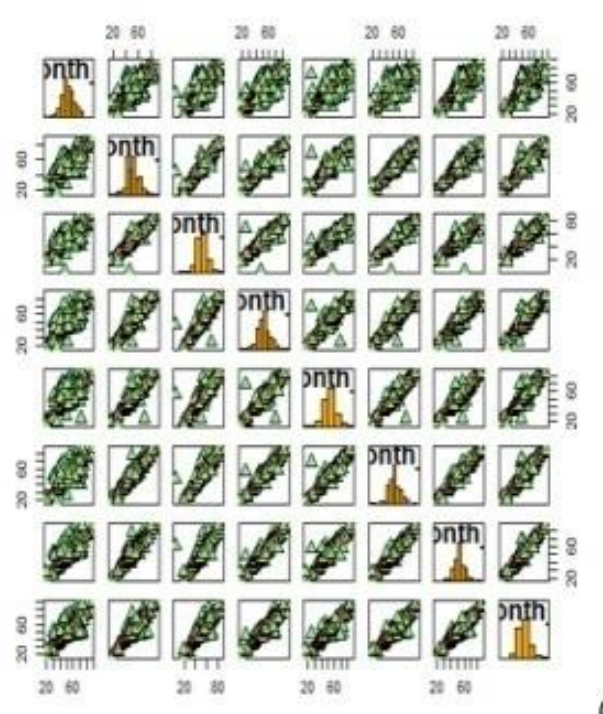

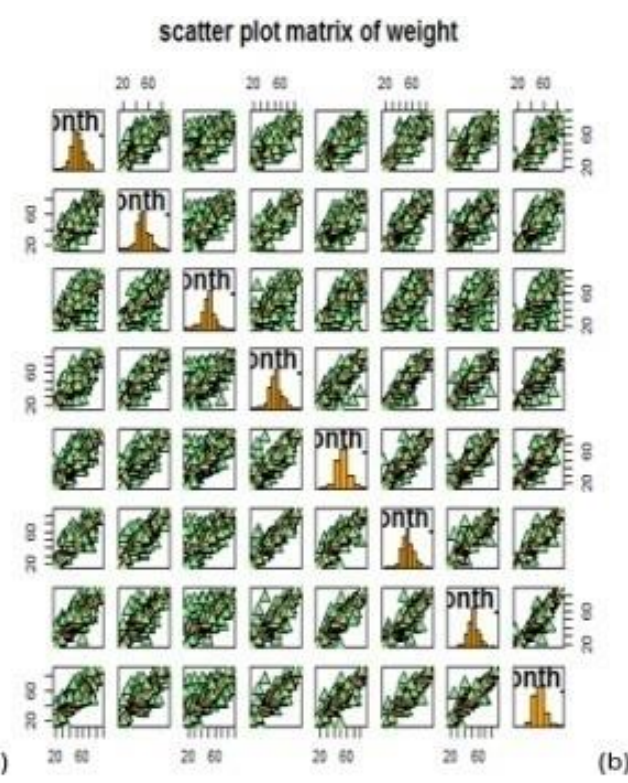

Fig. 8: Scatter plot of correlation matrix, (a) $\sqrt{C D 4^{+} \text {count, }}$, (b) body weight

\section{Covariance structure for $\sqrt{\mathrm{CD4}^{+} \text {count }}$ and body} weight- Covariance structures should be carefully selected to obtain valid inferences for the parameters of fixed effects in the model. If one ignores important correlations by using a model that is too simple, one risks increasing type I error rate and underestimates standard errors. On the other hand, if the model is too complex, power and efficiency are sacrificed.

The data used for the two responses variables is unbalanced, since subjects are measured at different time points and the number of measurements is different across subjects, but had the same time points across subjects.
To choose the most appropriate covariance structure for the two responses, we have proofed this through model fit statistics by covariance structure matrix to compare the values of AIC, AICC and BIC. The smallest of these values was preferred and becomes the covariance structure and used to model the residual error. Therefore; from the possible covariance structures in fitting the linear mixed model based on the maximum likelihood (ML) and restricted maximum likelihood (REML) covariance parameter estimates and the minimum AIC, AICC and BIC values the unstructured (UN) covariance structure is selected for $\sqrt{\mathrm{CD}^{+} \text {count }}$ and compound symmetry for body weight. 
Table 10: Covariance Structure for square root CD4 cell count

\begin{tabular}{cccccc}
\hline $\begin{array}{c}\text { Covariance } \\
\text { structure }\end{array}$ & Unstructured & Simple & $\begin{array}{c}\text { Compound } \\
\text { symmetry }\end{array}$ & Autoregressive $(\operatorname{ar}(\mathbf{1}))$ & Toeplotize \\
\hline AIC & $\mathbf{2 0 2 7 8 . 9}$ & 26888.4 & 22254.4 & 21142.2 & 21018.7 \\
AICC & 20279.5 & 26888.4 & 22254.4 & 21142.2 & 21018.7 \\
BIC & $\mathbf{2 0 4 3 3 . 1}$ & 26892.7 & 22263.0 & 21150.8 & 21053.0 \\
\hline
\end{tabular}

Table 11: Covariance Structure for Body Weight

\begin{tabular}{cccccc}
\hline $\begin{array}{c}\text { Covariance } \\
\text { structure }\end{array}$ & Unstructured & Simple & $\begin{array}{c}\text { Compound } \\
\text { symmetry }\end{array}$ & $\begin{array}{c}\text { Autoregressive } \\
\text { (ar(1)) }\end{array}$ & Toeplotize \\
\hline AIC & 22901.8 & 30238.1 & 21932.9 & 22906.2 & 22576.4 \\
AICC & 22901.8 & 30238.1 & 21933.6 & 22906.2 & 22576.5 \\
BIC & 22910.4 & 30242.3 & 22087.1 & 22914.8 & 22610.7
\end{tabular}

\section{Variable Selection Techniques for $\sqrt{C D 4^{+} \text {coun }}$ and} body weight- The model development process was carried out by selecting covariates that have the potential to be included in the linear mixed models. Fitting a longitudinal model by using the $\sqrt{C D 4^{+} \text {counts }}$ and body weight response variables and including all the main effects, two factor interactions with time. In this study, we used backward selection starting from the full model that includes all covariates and two way interaction with time. This means that, the main effect and main effect by time interactions to explore the relationship between responses, which $\sqrt{C D 4^{+} \text {counts }}$ and body weight with each of the covariates. For this analysis nine categorical and three continuous variables were considered with the two response variables. There are the same covariates for the response variables $\sqrt{C D 4^{+} \text {counts }}$ and body weight. Variables shows significant at 0.25 level for time, sex, age, $\mathrm{BMI}$, baseline CD4 count, educational status, functional status, duration of ART, WHO clinical stage, ART regimen class, marital status, residence, opportunistic infection and the interaction terms of time, sex, age, BMI, baseline CD4 count, educational status, functional status, duration of ART, WHO clinical stage, ART regimen class, marital status, residence, opportunistic infection with time for both responses. But, for the purpose of study the variation in the main effects, we have to include all main effects for analysis. After removing the interactions with time independent variables from the model, the least significant interactions variables from this full model at $5 \%$ level of significant, removed this interactions variable to use the ML estimation method. One the most appropriate approach was to eliminate the interactions one at a time, starting with the least significant interaction. By using the model fit statistics such as AIC, Log Likelihood and BIC then we must use the ML estimation method. However, after the final model is chosen, refit the model using REML because REML estimators are superior to ML.

\section{DISCUSSION}

This study attempted to examine the impact of ART and some demographic and clinical factors for the progression of $\mathrm{CD}^{+}$count and body weight of HIV/AIDS patients over time in DBRH. Longitudinal analysis of progression of $\mathrm{CD} 4^{+}$count and body weight for HIV/AIDS patients initiated to ART.

The data normality was tested using Shapiro-Wilk test of normality the square root transformation for $\mathrm{CD}^{+}$count and the actual body weight were satisfied. The two continuous response variables HIV/AIDS data were analyzed using different plots (exploratory analysis) followed by model based outputs. From the profile plots, we observed the existence of variability in $\mathrm{CD}^{+}$count within and between individuals. The exploratory analysis result for the mean structure also suggested that on average, $\mathrm{CD}^{+}$cell count was increased in a linear pattern 
over time. This study supported by the Gezie ${ }^{[19]}$, who described in his study, WHO identified that after the patients initiated to the ART their $\mathrm{CD}^{+}$cell count was increased. This might be as the $\mathrm{CD} 4^{+}$cell count increased the progression of a disease decreases as the immune system of a patient may develop disease resistance.

In harmony to this result given by Liu et al. ${ }^{[21]}$, indicated that baseline $\mathrm{CD}^{+}$, age and time were significant determinants of $\mathrm{CD}^{+}$cell count progression, but contradicts with functional status. The significance of sex as a predictor for $\mathrm{CD4}^{+}$cell count was also supported by previous researches ${ }^{[20,22-25]}$ but not supported by Gezie [19].

Duration of treatment was among the significant determinant factors of the current $\mathrm{CD}^{+}$ cell count, for patients on ART. It means that when duration of treatment was increased patients on ART shows improvement of their $\mathrm{CD}^{+}$cell counts; indicates that a better health condition. This result was also supported by Michael [26]; Montarroyos et al. [27]; and Ogoina et al. ${ }^{[28]}$ these described that WHO reported that $\mathrm{CD}^{+}$cell counts can be improved by duration of treatment ${ }^{[29,30]}$.

In accordance to Reda et al. ${ }^{[31]}$; Valeria and Makory ${ }^{[32]}$ also showed a significant effect on square root of $\mathrm{CD}^{+}$ count by sex and age of patients. Age is significant effect on $\mathrm{CD}^{+}$count with estimated value of 0.0059 . Similarly to the current result ${ }^{[33]}$ also found that age of patients were significant effects on CD4+ count in North West Ethiopia. Moreover, marital status of individual has no significant effect on square root of $\mathrm{CD}^{+}$count, where similar findings was reported by some previous scientists but contradicted with ${ }^{[32]}$ findings.

A higher baseline BMI predicts greater gains in $\mathrm{CD}^{+}$cell counts with the estimated value (0.0109) and $p$-value $(0.008)$ at $5 \%$ significance level. This finding is also supported by previous studies in different countries [33,34]. Therefore, persons with higher BMI might naturally have higher $\mathrm{CD}^{+}$cell counts, and the greater $\mathrm{CD} 4+$ cell count recovery on ART in HIV- infected patients with higher BMI could be explained as a "return to health" phenomenon.

The residence was significant effect on $\mathrm{CD}^{+}$with inpvalue 0.0187 and the responses were higher for urban adult patients than rural areas through time. Similar to these findings i.e. Valeria and Makory ${ }^{[32]}$ suggested that the long distance of the rural areas from health institutions, and patients in these areas may come after high destruction of $\mathrm{CD}^{+}$cells by HIV.

The two levels of patients' baseline functional status (working and ambulatory patients) were found statistically non-significant different both in their initial status (intercept) and linear change (slope) of their CD4 ${ }^{+}$ cell count as compared with the third level, bedridden patients. On the contrary, other studies shown that there was a significant association between functional status and change of $\mathrm{CD}^{+}$cell count ${ }^{[33]}$. In the other case, opportunistic infections at the start of ART were significant. Likewise, Kim et al. ${ }^{[34]}$ also reported that opportunistic infections during the treatment period could affect the $\mathrm{CD} 4^{+}$count change over time. Thus, patients who were at a 'working' status could be in a better position about co-infection and similar reasons that could influence the response to ART than their counterparts (bedridden).

From the final model of body weight, predictors such as time, sex, age, opportunistic infection, WHO clinical stage, $\mathrm{BMI}$, baseline $\mathrm{CD} 4^{+}$cell count, duration of ART, and interaction effects of functional status, WHO clinical stage, BMI, baseline $\mathrm{CD}^{+}$count, duration of ART and marital status with time ( $p$-value $=0.0287,0.0001$, $0.0036,0.002,<.0001,0.0037,0.036,0.0365,0.0415$, $0.0002,0.0029,0.0275,0.0042$ and 0.0021 ; respectively) are among the significant predictors of body weight progression at $5 \%$ significance level.

In support of the current results, also found that baseline $\mathrm{CD}^{+}$cell count was significantly affected on body weight. In harmony to current results, Kim et al. [34] reported with increasing $\mathrm{CD}^{+}$cell count change and increase in body weight was observed when patients were under the follow up of HAART in central Kigali, Rwanda. Similarly, Wang et al. ${ }^{[33]}$; Kim et al. ${ }^{[34]}$ showed that lower CD4 lymphocyte cell counts were associated with lower weight. Similar to the current found that age and WHO clinical stage were significant determinants of body weight change.

\section{CONCLUSIONS}

This study was considered on HIV-positive patients attending ART and the data found from DBR Hospital ART clinic between September 2014 and August 2017. To undergoing the main study objective of conducting on longitudinally measured $\mathrm{CD}^{+}$ Cell counts and body weight on a retrospective study of HIV-positive patients under ART. Also, on the interest of 
finding and on exploring the progression $\mathrm{CD}^{+}$cell count and body weight through time of HIV-positive patients, which were under ART. The mean $\mathrm{CD}^{+}$cell count of HIV positive patients increases with an increasing rate until time point four then decreases from time point four to time point five and also increase from time point five to six then increase until to the final time point seven five. ART is not free from AIDS but it greatly improves the health condition of HIV/AIDS patients. The numbers of categorical variables across follow up time points are not different. The $Q-Q$ plot and box plots suggests square root transformation of the data is appropriate.

Further studies are recommended to expand understanding and knowledge on the joint analysis of longitudinal data as well as include more clinical and epidemiological covariates.

\section{ACKNOWLEDGMENTS}

The authors expressed their heart full thanks to the Debre Berhan Referral hospital for their cooperation and contribution of their administration, arrangements as the successful study.

\section{CONTRIBUTION OF AUTHORS}

Research concept- A.R. Muralidharan

Research design- A.R. Muralidharan

Supervision- Ayele Admasu

Materials- A.R. Muralidharan

Data collection- A.R. Muralidharan

Data analysis and Interpretation- A.R. Muralidharan

Literature search- A.R. Muralidharan

Writing article- A.R. Muralidharan

Critical review- Ayele Admasu

Article editing- A.R. Muralidharan

Final approval- Ayele Admasu

\section{REFERENCES}

[1] WHO. Consolidated guidelines on the use of antiretroviral drugs for preventing and treating HIV infection 2013; pp. 52-64.

[2] WHO. Regional Office for South-East Asia New Delhi, laboratory guidelines for enumerating CD4+ $T$ lymphocytes in the context of HIV/AIDS, 2007; pp. 24-36.

[3] Addisu A, Dagim A, Tadele E, Adissu A, Mussie A, et al. CD4 cell count trends after commencement of antiretroviral therapy among HIV infected patients in Tigray, northern Ethiopia: A retrospective Cross- sectional study. PLoS One, 2015; 10(3): e0122583. doi: 10.1371/ journal.pone.

[4] Ebonyi OA, Agbaji OO, Anejo-Okopi AJ, Oguche S, Agaba $A P$, et al. Factors associated with a low CD4 count among HIV-1 infected patients at enrolment into HAART in Jos, Nigeria. Br J Med Res., 2016; pp. 1-9.

[5] Muralidharan AR, Fasika-Melese MS. A survival analysis of HIV/AIDS patients in the case of debre berhan referral hospital, IJEMMASSS, 2019; 1(1): 09-29.

[6] Awoke T, Worku A, Kebede Y, Kasim A, Birlie B, et al. Modeling Outcomes of First-Line Antiretroviral Therapy and Rate of CD4 counts change among a cohort of HIV/AIDS Patients in Ethiopia: A retrospective cohort study. PLOS ONE, 2016; 11(12): e0168323. doi: 10.1371/journal.pone.0168323.

[7] Batterham MJ, Garsia R, Greenop P. Prevalence and predictors of HIV-associated weight loss in the era of highly active antiretroviral therapy. Int J Std AIDS, 2002; 13(11): 744-47. doi: 10.1258/095646202 320753682.

[8] Biadgilign S, Reda AA, Digaffe T. Predictors of mortality among HIV infected patients taking antiretroviral treatment in Ethiopia: A retrospective cohort study. AIDS Res Ther., 2012; 9(1): 15. doi: 10.1186/1742-6405-9-15.

[9] Bijleveld, C, Vanderkamp L, Mooijaart A, Van der Kloot W, Van der Leeden R. Longitudinal Data analysis: designs, models \& methods, Sage publications, 1999.

[10]Cauldbeck MB, O'Connor C, O'Connor MB. Adherence to anti-retroviral therapy among HIV patients in Bangalore, India. AIDS research and therapy, country profile Ethiopia. Accessed on 20 January 2018, http://www.pepfar.gov/pepfar/ organization/81660.pdf.

[11]Diggle $P$, Heagerty $P$, Liang K. Analysis of Longitudinal Data. $2^{\text {nd }}$ ed. Oxford, United Kingdom: Oxford University Press, 2002.

[12] Hedeker DR, Gibbons RD. Longitudinal Data Analysis. J. Wiley and Sons, 2006.

[13]Grunfeld C. What Causes Wasting in AIDS? N Engl J Med., 1995; 333(2): 123-34. doi: 10.1056/NEJM1995 07133330210. 
[14]Hosmer D, Lemeshow S. Applied logistic regression. New York: John Wiley and Sons, Inc., 1989; pp. 37681.

[15]UNAIDS. Report on the Global AIDS Epidemic. Tech. Rep., 2010-2017.

[16]UNAIDS/WHO. AIDS epidemic update. Geneva: UNAIDS, WHO, 2011.

[17]Kebede M, Zegeye D, Zeleke B. Predictors of CD4 Count Changes after Initiation of Antiretroviral Treatment in University of Gondar Hospital, Gondar in Ethiopia, Japan. Clin Res HIV/AIDS, 2014; 1(2): 1008.

[18]Laird N, Ware J. Random-effects models for longitudinal data. Biometrika, 1982.

[19]Gezie LD. Predictors of CD4 count over time among HIV patients initiated ART in Felege Hiwot Referral Hospital, northwest Ethiopia: multilevel analysis. BMC Res Notes, 2016; 9: 377. doi: 10.1186/s13104-016-2182-4.

[20]Littell R, Milliken G, Stroup W, Wolfinger R, Schabenberger O. SAS for Mixed Models, Second Edition, Cary, NC: SAS Institute Inc. 2006; pp. 363-65.

[21] Liu E, Spiegelman D, Semu H, Hawkins C, Chalamilla $\mathrm{G}$, et al. Nutritional status and mortality among HIVinfected patients receiving antiretroviral therapy in Tanzania. J Inf Dis., 2011; 204(2): 282-90.

[22]Macro International Inc. Ethiopia atlas of key demographic and health indicators 2005. 2008; pp. 1-31.

[23]Mangili A, Murman D, Zampini AM, Wanke C. Nutrition and HIV Infection: Review of weight loss and wasting in the era of highly active antiretroviral therapy from the nutrition for healthy living cohort. CID, 2006; 42: 836-42.

[24]Melinda R. How CD4+ counts help treat HIV and AIDS2016. Available from http://www.webmd.com/ hiv-aids/CD4+-count-what-does-it-mean.

[25]Mesfin H, Tenaye T. Assessment of ART outcomes versus CD4+ cell count threshold among HIV/AIDS patients. J Inf Dis., 2015.

[26]Michael P. Longitudinal Data Analysis with Discrete and Continuous Responses, SAS Institute Inc., 2002; pp. 065-47.
[27]Montarroyos R, Miranda-Filho C, Ce'sar C, Souza V, Lacerda $\mathrm{R}$, et al. Factors related to changes in CD4+ T-Cell counts over time in patients living with HIV/AIDS: A multilevel analysis. PLoS ONE, 2016; 9(2): 0084276. doi: 10.1371/journal.pone.0084276.

[28] Ogoina D, Obiako RO, Muktar HM, Adeiza M, Babadoko A, et al. Morbidity and mortality patterns of hospitalized adult HIV/AIDS patients in the era of highly active antiretroviral therapy: A 4-year retrospective review from Zaria, Northern Nigeria. AIDS Res Treat., 2012; 10.

[29] Olawumi O, Olatunji P, Salami A, Odeigah L, Iseniyi J. Effect of highly active antiretroviral therapy on CD4+ count and weight in aids patients seen at the uith, Ilorin, 2008.

[30]Palombi L, Marazzi MC, Guidotti G, Germano P, Buonomo $\mathrm{E}$, et al. Incidence and predictors of death, retention, and switch to second-line regimens in antiretroviral-treated patients in sub-saharan african sites with comprehensive monitoring availability. Clin Inf Dis., 2009

[31]Reda AA, Biadgilign S, Deribew A, Gebre B, Deribe K. Predictors of Change in CD4 lymphocyte count and weight among HIV Infected Patients on antiretroviral treatment in Ethiopia: A Retrospective Longitudinal Study. PLoS ONE, 2013; 8(4): e58595. doi: 10.1371/journal.pone.0058595.

[32] Valeria DR, Makory NB. Longitudinal study of change in CD4+ Cell counts on HIV positive patients initiated on antiretroviral therapy at the comprehensive care centre in Kenyatta National Hospital, W62/68997/ 2011, 2014.

[33] Wang H, Wolock T, Carter A, Nguyen G, Kyu H. Gakidou Estimates of global, regional, and national incidence, prevalence, and mortality of HIV, 1980-15. The Global Burden of Disease Study, 2016; 3: e36187.

[34] Kim KH, Yi J, Lee HS. The CD4 slope can be a predictor of immunologic recovery in advanced HIV Patients: a case control study. J Intern Med., 2015; 30(5): 705-13. 